\title{
MULTIMODALIDADE E LEITURA CRÍTICA: NOVAS PERSPECTIVAS PARA O ENSINO DE LÍNGUA PORTUGUESA ${ }^{1}$
}

\author{
Marcos NONATO DE OLIVEIRA \\ (Universidade do Estado do Rio Grande do Norte) \\ marcosnonato.uern@gmail.com
}

\begin{abstract}
Resumo: A forte presença multimodal nos eventos comunicativos na pósmodernidade passou a exigir dos sujeitos novas habilidades leitoras. A relação entre os modos semióticos verbais e não verbais presentes nos textos criaram novas possibilidades de leitura crítica, fazendo surgir à necessidade de uma abordagem multimodal na sala de aula, principalmente nas aulas de língua portuguesa. Este trabalho apresenta os resultados de uma pesquisa-ação, realizada com uma turma do $9^{\circ}$ ano do Ensino Fundamental, na área de leitura. O foco desse estudo é mostrar o desenvolvimento de leitura dos alunos, a partir de um trabalho de intervenção realizado com a multimodalidade textual. Trata-se de uma pesquisa interventiva de caráter qualitativo e descritivo. Como instrumentos de coleta de dados empregamos questionário, sequências didáticas, notas de campo e entrevista. A análise dos dados ocorreu por amostragem. Apenas dez alunos participaram efetivamente da pesquisa. Nesta pesquisa, buscamos trabalhar atividades dentro de um processo dinâmico, procurando construir o sentido a partir de um processo interativo entre todos os elementos multimodais que constituem os textos. Os resultados deste processo investigativo mostram que no período da intervenção, de forma gradual, os alunos, que antes priorizavam apenas os fatores verbais durante a leitura, passaram a considerar os demais elementos multissemióticos, que compõem os textos, tornando assim, o processo de atribuição de sentido mais detalhado e criterioso. Nesse sentido, destacamos que o trabalho com a multimodalidade mostrou-se um caminho para tornar os alunos leitores mais ativos.
\end{abstract}

Palavras-Chave: Leitura. Multimodalidade. Ensino. Língua portuguesa. Leitores críticos.

\section{MULTIMODALITY AND CRITICAL READING: NEW PERSPECTIVES TO PORTUGUESE LANGUAGE TEACHING}

Abstract: A strong presence of multimodality in communicative events in postmodernity has required the development of new skills for proficient reading. The relationship between verbal and non-verbal semiotic modes present in the texts has created new possibilities for critical reading, giving rise to the need for a multimodal approach in the classroom, especially in Portuguese classes. This paper presents the results of an action research study on reading which was conducted with a group

\footnotetext{
1 Artigo elaborado a partir de dissertação de mestrado (LIMA, 2015) realizada no Programa de Mestrado Profissional em Letras - PROFLETRAS.
}

Pensares em Revista, São Gonçalo-RJ, n. 6, pág. 145-162, jan. / jun. 2015

DOI: $10.12957 /$ pr.2015.17192 
of 9th grade students of elementary school. The focus of this study is to show the development of students' reading skills, as the outcome of an interventionist teaching based on textual multimodality. In order to generate data, a questionnaire was applied and interviews were carried out. The results of this investigative process show that during the pedagogical intervention the students who once prioritized only the verbal factors while reading, gradually began to consider other multisemiotic elements that make up the multimodal texts; thus making the meaning making process more sense detailed and insightful. In this regard, we emphasize that working with multimodality proved to be a way to make the most active readers students.

Keywords: Reading. Multimodality. Meaning making. Critical readers.

\section{Introdução}

Estudos e pesquisas têm sido realizados, nos últimos anos, buscando respostas para os processos responsáveis pelo desenvolvimento da leitura e pelo melhoramento da sua efetividade no ensino. É consenso entre os estudiosos que o fazer pedagógico precisa ser revisto, de forma a tornar a leitura um meio capaz de levar o indivíduo a construir seu próprio conhecimento e exercer seu papel social. A leitura, nessa perspectiva, é considerada como um recurso que propicia a reflexão crítica e a troca de ideias. As tecnologias vêm influenciando a forma como as pessoas têm interagido com o mundo que as cercam e os avanços tecnológicos vêm tornando as formas de comunicação mais rápidas e multimodais. E essas características têm se refletido nos textos, que se tornaram cada vez mais multissemióticos, ou seja, formados por linguagens variadas, constituídos por palavras, imagens, cores, sons, gestos, entre outros, que se integram na constituição do sentido. Se a constituição dos textos mudou, a nossa maneira de ler deve ser revista. O processo de leitura não pode ser pautado apenas nos fatores verbais. $\mathrm{O}$ ato de ler deve amplia-se e considera todos os elementos empregados pelo autor na construção do texto. As mudanças ocorridas nos textos geraram a necessidade da realização de novos estudos a respeito dos elementos multissemióticos que estão constituindo a comunicação na sociedade atual.

Trabalhar com a compreensão leitora como uma atividade social e dinâmica implica ressaltar o caráter multifacetado da leitura, só assim, é possível reformular práticas e comportamentos realizados dentro da escola e assumir seu papel social 
(VAN DIJK, 2011). Assim, pretendemos focalizar a importância do ensino de leitura como ferramenta capaz de contribuir para despertar a autonomia e a consciência crítica, capacitando os alunos para realizarem leituras que vão além do entendimento superficial. Para isso, destacaremos a natureza dinâmica e multifacetada dos textos que pertencem a diversos gêneros discursivos, através dos quais os sujeitos sociais interagem com o mundo globalizado. O objetivo deste estudo é investigar o ensino crítico de leitura e a multimodalidade textual no que se refere à formação de leitores proficientes nas aulas de Língua Portuguesa.

\section{1 - A formação do leitor crítico nas aulas de língua portuguesa}

Um dos pressupostos defendidos pelos estudiosos da linguagem é que o ensino de língua portuguesa deve proporcionar o desenvolvimento da autonomia do aluno no processo de leitura, como resultado do domínio do funcionamento da linguagem em diversos momentos de comunicação. Rojo (2012), destaca que as práticas de linguagem são socialmente situadas e que não é possível compreender os textos fora dos contextos sociais e históricos. Assim, o ensino de língua portuguesa precisa ressignificar a noção de texto, cujo foco era o verbal e passar a considerar a diversidade de arranjos que a escrita tem apresentado em função das mudanças nas formas de comunicação. Em consequência dessas mudanças, nossos modos de ler os textos estão sendo reelaborados. Segundo Dionísio (2006, p. 138), frequentemente se observa a combinação de material visual com a escrita, cada modo de representação da linguagem deve ser considerado no momento da leitura. "Todos os recursos utilizados na construção dos gêneros textuais exercem uma função [...] na construção de sentidos dos textos." Os sentidos dos textos não podem ser construídos considerando-se apenas os aspectos verbais.

É preciso perceber que as imagens (estáticas ou dinâmicas) e os sons são concluintes de uma obra que, ao considerá-los, a elaboração de sentidos tomará muitos outros caminhos além daquele formado estritamente pelas palavras. Com isso, os textos passam a ser entendidos como 'modos de dizer' que não precisam ser exclusivamente escritos: podem também apresentar elementos visuais e sonoros ou acontecer formas estáticas ou em movimento, como vemos em filmes ou propagandas. [...] isso construiria a multimodalidade ou multissemiose dos textos, as quais instauram várias possibilidades de construção de sentido (ROJO, 2012, p.182). 
Essa forma de conceber texto é consequência das novas práticas de leitura e escrita suscitadas pelas inovações sociais que criam a necessidade de novas reflexões sobre o ensino e a formação do leitor nas aulas de língua portuguesa. Para Rojo (2012), as novas práticas sociais demandam leitores mais críticos que sejam capazes de ler e atribuir sentido a textos cada vez mais multissemióticos, resultantes dos avanços tecnológicos. Nesse sentido, a formação do leitor deve partir do pressuposto de que a construção de significados não se limita ao processo de decodificação. A leitura e a produção de significados podem variar na medida em que as semioses são organizadas e reorganizadas dentro dos textos. Além disso, é fundamental que os alunos entendam que os sentidos são produzidos numa conexão entre o processo histórico, político, social e do contexto de produção da obra. A esse respeito, os PCN (2010, p. 70) acrescentam: "o leitor competente é capaz de ler as entrelinhas, identificando a partir do que está escrito, elementos implícitos [...]". Para que o processo de leitura seja ampliado, o sujeito precisa ter competência para estabelecer relações entre os seus conhecimentos prévios e o texto, refletindo sobre as informações transmitidas. Um leitor crítico é capaz de atribuir valor as informações veiculadas, construindo assim, o seu posicionamento.

Rojo (2012, p.152) afirma ainda que a leitura é ressignificada a cada momento graças a seus leitores, as situações comunicativas e as novas práticas digitais, multimodais e multimidiáticas de letramento. O ensino de língua materna precisa promover novas práticas pedagógicas que contemplem os atuais letramentos que inovam as relações sociais. As novas relações sociais e históricas e os instrumentos multissemióticos estão impulsionando a escola, e mais especificamente a disciplina língua portuguesa a trabalhar com foco no desenvolvimento de competências de leitura que envolvam diferentes semioses como "imagens estáticas ou em movimento, as cores, os sons os efeitos computacionais, etc.".

A leitura, de acordo com Freire (2005), é responsável pela ampliação do conhecimento de mundo, por isso, exige interlocutores capazes de perceber traços ideológicos nos textos, bem como compreender os contextos em que eles são elaborados. A leitura precisa possibilitar a formação de alunos questionadores e reflexivos. Dessa forma, a escola tem como tarefa articular situações nas quais a capacidade de processar informação transmitida por uma combinação de formas de representação seja considerada. 
Tendo em vista que as práticas pedagógicas podem exercer influência na formação leitora dos alunos, procuramos nessa pesquisa incentivar a leitura e interpretação de textos multimodais, como estímulo para a formação de leitores críticos. Partimos do pressuposto de que os textos são sempre multimodais, cujo sentido resulta da interação de vários modos de representação. Acreditamos que a ampliação da ideia de leitura possibilitará aos alunos a expansão e a construção de capacidades leitoras.

Os avanços tecnológicos trouxeram mudanças significativas não só para as relações sociais e para as formas de interação entre as pessoas, mas também têm exigido novas práticas de letramento. Exigem o desenvolvimento de novas habilidades de leitura e de escrita ampliando a noção de letramento para multiletramentos. As pessoas devem estar aptas a compreender, ou melhor, a elaborar sentido e significação diante dos mais diversos tipos de textos construídos com base nas mais distintas modalidades da linguagem (escrita, oral e, sobretudo, não verbal/ imagética). Tais capacidades refletem a essência da perspectiva dos multiletramentos (DIONÍSIO, 2006).

O acréscimo do prefixo 'multi' ao termo letramento, segundo Rojo (2012), não se limita a questões referentes à multiplicidade de práticas de leitura e escrita que marcam a sociedade atual: envolve a diversidade de linguagens, semioses e mídias responsáveis pela produção de textos multimodais e pela pluralidade cultural trazida pelos leitores contemporâneos. Os multiletramentos estão relacionados à diversidade de culturas e de linguagens incorporadas ao nosso cotidiano graças aos avanços tecnológicos. Nosso meio social é eminentemente marcado pelo plurilinguismo e pela multissemiose. Para uma abordagem pluralista da cultura e da linguagem, é necessário considerarmos os multiletramentos e seus pressupostos. De acordo com Rojo (2012, p. 13),

O conceito de multiletramentos aponta para dois tipos específicos e importantes de multiplicidade presentes em nossas sociedades, principalmente as urbanas, na contemporaneidade: a multiplicidade cultural das populações e a multiplicidade semiótica de constituições dos textos por meio dos quais ela se informa e se comunica.

Os textos que circulam no nosso meio são misturas de várias culturas oriundas de diferentes letramentos que se caracterizam por escolhas pessoais e políticas. A produção cultural atual é marcada pela hibridização onde cada pessoa pode criar sua própria coleção. Existe uma apropriação múltipla dos patrimônios culturais 
(ROJO, 2012). No que se refere à multiplicidade de semioses é uma característica dos textos de circulação social. Os textos apresentam imagens, arranjos de diagramação, cores, formato das letras, movimentos, sons etc. É o que chamamos de multissemiose que exige multiletramentos. Os textos são construídos por muitos modos semióticos, cuja produção e significação necessitam de habilidades específicas para se interagir com cada um deles.

O termo multiletramentos surgiu no intuito de englobar as atuais discussões referentes às novas pedagogias do letramento e difere do conceito de letramentos por este se referir à multiplicidade e variedade das práticas letradas da nossa sociedade e aquele fazer referência tanto à multiplicidade cultural quanto à semiótica de constituição dos textos (ROJO, 2012). No que se refere à multiplicidade de culturas, García (2008 [1989]) enfatiza que as produções culturais atuais são marcadas por textos híbridos, oriundos de diferentes letramentos e de diferentes campos. Segundo o autor, as misturas têm assumido um lugar de destaque, abrindo espaço para novas formas de comunicação privilegiando as variedades de uso da linguagem. Quanto à multiplicidade de linguagens (modos, semioses) presentes nos textos em circulação, segundo Rojo (2012, p. 21), é o que constitui a multimodalidade que exige multiletramentos, ou seja, novas capacidades para leitura e compreensão.

[...] são necessárias novas ferramentas - além das da escrita manual (papel, pena, lápis, caneta, giz e lousa) e impressa (tipografia, imprensa) - de áudio (vídeo, tratamento de imagem, edição e diagramação). São requeridas novas práticas - de produção, nessas e em outras, cada vez mais novas, ferramentas de análise crítica [...].

Nesse caso, é preciso desenvolver nos alunos competências voltadas para o domínio de práticas letradas em relação à linguagem em suas variadas combinações. Os multiletramentos exigem e incentivam a preparação de um aluno crítico, autônomo, sujeito de sua aprendizagem, e criador de sentido. O aprendiz tem que aprender a interagir em ambientes interativos cujos textos são multissemióticos. Uma das habilidades para interagir nesses ambientes é ter conhecimentos sobre os modos semióticos e entender que a escolha com base na combinação de imagens, sons e/ou palavras depende de propósitos e contextos definidos. Assim, são essenciais novas práticas, tanto de produção quanto de análise crítica (ROJO, 2012). 
O termo multiletramentos é citado por Rojo (2012) em referência ao The New London Group (GNL), um grupo de pesquisadores que estudava os letramentos. Em 1996, esses pesquisadores se reuniram em Londres durante uma semana e lançaram um manifesto - A pedagogy of multiliteracies- Designing social futures que afirmava a necessidade da escola trabalhar voltada para uma pedagogia dos multiletramentos, levando em consideração a grande variedade de culturas presentes nas salas de aulas. Os participantes do GNL eram oriundos de países que enfrentaram problemas com conflitos culturais. O grupo destacava ainda a urgência dos jovens terem acesso às ferramentas da comunicação de caráter multissemiótico.

Rojo (2012) destaca algumas características referentes aos multiletramentos: a) "são interativos (colaborativos); b) fraturam e transgridem as relações de poder estabelecidas em especial as relações de propriedade (das máquinas, das ferramentas, das ideias, dos textos (verbais ou não); e c) são híbridos, fronteiriços, mestiços (de linguagens, modos, mídias e culturas)." Essas características tornam urgente uma nova forma de conceber, produzir e ler os textos, ou seja, o processo de leitura e criação textual não é mais unicamente linguístico, e sim relaciona imagem, cores, som, formato das letras. Nesse sentido, a leitura envolve diferentes linguagens e suas combinações que estão presentes no mundo sociocultural. Para interagir com esses novos processos, é preciso estabelecer relações diferenciadas no ato de leitura. Dessa forma, percebe-se que a linguagem é organizada em torno de um contexto, no qual, segundo Kress e van Leeuwen (2006), tanto autor quanto leitor escolhe um modo semiótico, dentro de uma variedade de possibilidades para dar destaque a sua produção.

Segundo Hamilton e Barton (2000), os multiletramentos ampliam as possibilidades de leitura e de escrita, considerando as práticas efetivas que estão ligadas a modos culturais mais amplos. Assim, a prática pedagógica precisa considerar a dimensão complexa das práticas sociais de uso da linguagem. Lemke (2000) destaca que os multiletramentos podem ser ensinados, desde que professores e alunos estejam conscientes dos fatores sociais, contextuais históricos e culturais que os constituem.

Rojo (2010, p.138) informa que devido às novas formas de aprendizagem e das novas possibilidades de ensino pós-modernas, que se busque incorporar uma 
pedagogia dos multiletramentos, levando em consideração pedagogias específicas, que envolvam todas as formas de linguagem (verbal e não verbal), tendo como foco o aprendiz, que passa a ser o principal nesse processo dinâmico de mudança e de produção de conhecimento. Em nossa pesquisa, partimos dessa nova proposta que destaca a importância de se considerar a aprendizagem de leitura e de escrita de textos multimodais que envolvem outras linguagens e novas práticas de comunicação e interação. "Novos modos de significar, de fazer sentido e de circular discurso na sociedade contemporânea convocam os multiletramentos." Os multiletramentos consideram a multimodalidade (linguística, visual, gestual, espacial e de áudio) e a diversidade de significados e contextos culturais (ROJO, 2012, p. 138).

\section{2 - Metodologia da pesquisa}

Nossa investigação está pautada na vertente da pesquisa-ação e caracterizase por uma intervenção na prática escolar, na qual o pesquisador é o professor que procurar refletir sobre sua prática, buscando formas para provocar mudanças na sua ação pedagógica e superar as dificuldades encontradas. Optamos por trabalhar com os alunos do 9ำ ano do Ensino Fundamental, jovens de faixa etária entre 13 e 15 anos, matriculados no sistema público de ensino do turno vespertino, num total de 24 alunos, sendo 09 meninos e15 meninas. Nossa decisão por trabalharmos com os jovens supracitados se fundamenta no fato de que os mesmos estão prestes a concluir um nível de ensino, e ainda apresentam algumas dificuldades relacionadas à compreensão leitora, principalmente à atribuição de sentido com mais aprofundamento crítico. Para a organização e análise dos dados selecionamos um grupo de 10 (dez) alunos ${ }^{2}$, dentre os 24 que compõem a turma que se envolveram na pesquisa. Os alunos selecionados apresentam competências semelhantes em relação à leitura. Todos os selecionados apresentam baixo nível de proficiência. Consideramos alunos proficientes aqueles que leem considerando todos os elementos (verbais e não verbais) e conseguem perceber intenções implícitas. O trabalho de intervenção que realizamos esteve centrado na prática de leitura de textos multimodais na sala de aula, a partir do desenvolvimento de atividades

\footnotetext{
${ }^{2}$ A seleção dos alunos foi realiza por amostragem aleatória simples. Atribuímos a cada participante um número único depois selecionamos os dez alunos de maneira casual.
} 
múltiplas e variadas. A referida proposta de trabalho se constitui em sequências didáticas e tem como base as propostas de Dolz e Schneuwly (2004).

\section{3 - Ação interventiva: lendo e interpretando textos multimodais}

Nosso objetivo, com essa atividade, é obter uma visão geral sobre a capacidade leitora dos estudantes em relação à multimodalidade textual, e, para isso, buscamos informações sobre a forma como os alunos leem esses textos. A seguir, apresentaremos a análise dos dados obtidos. Para realizarmos essa análise consideramos algumas respostas apresentadas pelos alunos nas questões propostas. A atividade de leitura que realizamos foi desenvolvida com a publicidade das sandálias Havaianas apresentada a seguir:

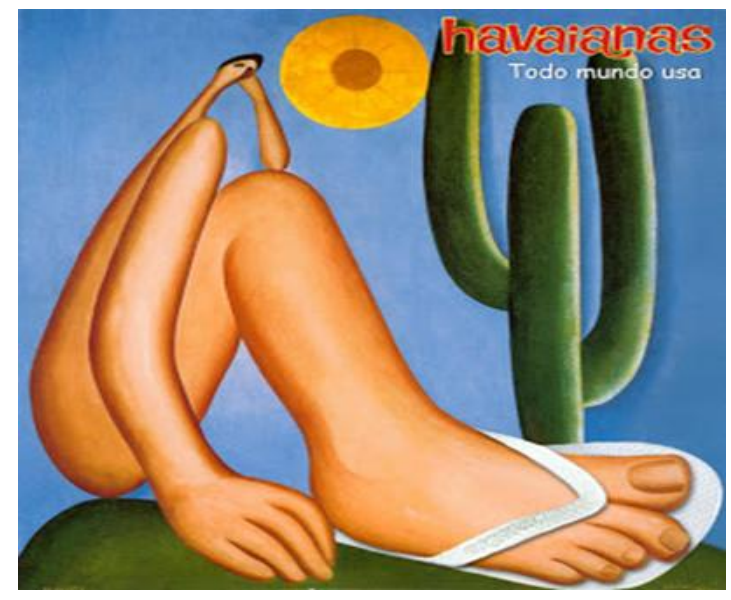

www.anunciospublictarios.com.br

O texto exposto acima apresenta como destaque o quadro Abaporu de Tarsila do Amaral, pintado em 1928, objetivando mostrar o exagero do corpo em contraste com a cabeça bem pequena. O quadro usado como suporte para a produção textual se tornou muito famoso e representativo do modernismo brasileiro. O nome da obra é de origem tupi-guarani que significa "homem que come gente" (canibal ou antropófago), uma junção dos termos aba (homem), pora (gente) e u (comer). O texto apresenta o quadro como estratégia para mostrar que as sandálias Havaianas são usadas por todos, sem exceção.

Para trabalharmos o referido texto, fizemos a exposição no Datashow e conversamos a respeito do texto, destacando informações sobre a pintura famosa 
que aparece como um dos elementos principais. Logo após a discussão, apresentamos as questões para que os alunos respondessem.

Dentre as questões apresentadas para estudo desse texto, indagamos a respeito da forma como os alunos realizavam suas leituras e que elementos eram considerados. As respostas indicam que alguns alunos têm ideia de que as imagens também são importantes na composição do texto. No entanto, verificamos que existem alunos que se detém apenas à parte verbal, ignorando os demais elementos do texto.

A1: Na parte escrita porque facilita o entendimento do leitor.

A2: Me baseei nos elementos verbais.

A3: Visual e verbal associando as duas linguagens fica melhor de entender.

A4: Na parte visual e na parte verbal. As duas juntas é que dão sentido ao texto.

A5: Nas duas linguagens. Na verbal e na visual.

A6: Considerei a parte escrita.

A7: Considerei todos os elementos.

A8: Li observando todos os elementos: imagem, cores e frases.

A9: Prestei mais atenção na parte escrita.

A10: Na parte verbal e na visual.

As respostas supracitadas revelam que alguns jovens afirmam que recorrem aos recursos verbais para atribuição de sentido ao texto. Alguns, entretanto, não percebem que o processo de atribuição de sentido fica prejudicado quando todos os elementos não são considerados durante o ato de ler. É preciso que haja a associação entre todos os elementos semióticos no momento da leitura, por isso, é necessário preparar o aluno para que ele consiga desenvolver capacidades leitoras e possa entender o sentido global dos textos lidos. Destacando a importância da leitura multimodal, Vieira (2007, p. 112) afirma que "o texto multimodal permite descrever e interpretar situações sociais representadas pelo produtor dos signos [...]". Nesse sentido, percebemos que é necessário um trabalho mais consistente da escola na direção de preparar o aluno para interagir com a diversidade textual que está a sua volta.

Questionamos também os alunos sobre os elementos que compõem o texto e sua importância no processo de atribuição de sentido. As afirmações dos alunos revelaram que a ideia de que a parte verbal é a principal ainda é muito forte. 
A1: Não, é preciso considerar todos os elementos presentes no texto.

A2: É necessário observar todos os elementos do texto.

A3: A parte escrita é a principal.

A4: Não, porque essa imagem quer mostrar a beleza da sandália.

A5: Não porque quer mostrar que todos, todos mesmo, usam as sandálias Havaianas.

A6: Não, todos os elementos do texto são importantes e devem ser lidos.

A7: É preciso ler todo o texto.

A8: A parte verbal precisa ser complementada com a parte não verbal.

A9: Não, é preciso considerar todas as partes do texto.

A10: Devemos considerar todos os elementos do texto.

Através das respostas supracitadas, alguns alunos citam a relevância da imagem na composição do texto, mas não explicam com clareza qual sua importância no processo de leitura e interpretação. No entanto, observando o texto, percebemos que a imagem usando as sandálias é a principal responsável pela divulgação das ideias do anunciante. As respostas dos alunos revelam que é preciso aprimorar as capacidades de leitura e atribuição de sentido, porque mesmos destacando os elementos visuais como necessários no texto, ainda falta uma definição mais clara do papel desses elementos na constituição do sentido. Só com a compreensão de que todos os modos semióticos presentes no texto são passíveis de leitura é que os alunos conseguirão realizar uma leitura com mais profundidade.

Outra questão que propusemos aos alunos foi sobre o sentido produzido pela frase que acompanha o anúncio. Queríamos verificar como os mesmos associam parte verbal e imagem. Por isso, interrogamos como se deu essa associação na leitura do anúncio das sandálias Havaianas.

A1: Que a sandália é muito popular e que todos usam.

A2: Quer Mostrar a popularidade da sandália.

A3: Que é preciso todo mundo usar a sandália.

A4: As Havaianas são bem populares e todos têm acesso.

A5: Porque é uma sandália que todo mundo pode comprar.

A6: Que a sandália é tão popular que até as pessoas que não existem usam.

A7: É que até mesmo uma pintura famosa está usando o produto do cartaz.

A8: A parte escrita mostra que as Havaianas são sandálias bem populares.

A9: O texto tenta mostrar que é uma sandália usada por figuras famosas.

A10: O texto quer mostrar que a sandália é barata e acessível a todos. 
Fica evidente pelas respostas dadas que alguns alunos não conseguiram entender a intenção do anúncio através da associação da imagem famosa com a frase que compõe o texto. Percebemos que falta uma leitura mais aprofundada no sentido de se compreender as implicações desses aspectos para a significação do texto. Mas, a ausência de referências aos fatores semióticos que formam o texto já demostra que esses jovens ainda não despertaram para a necessidade de realizarem leituras que extrapolem os aspectos verbais. De acordo com Dionísio (2006), a escola deve oferecer ferramentas de análise para além do senso comum e capacitar o aluno para relacionar significados a contextos. Esse resultado mostra que os alunos têm consciência da presença dos gêneros multimodais na realidade atual, mas faltam-Ihes as competências para poderem realizar uma leitura mais profunda.

Com o objetivo de observar como os alunos realmente fazem a leitura de um texto multimodal, ou seja, se conseguem ler de forma crítica e perceber o interesse que está por trás da composição do texto, relacionando todos os elementos que o compõem, solicitamos que os mesmos argumentassem sobre o objetivo do texto lido. Através das respostas, foi possível entender que os alunos, na sua maioria, conseguiram identificar que o objetivo do anunciante é vender o produto, entretanto, faltou-lhes compreender a carga ideológica, ou seja, as intenções, os valores socialmente construídos, marcados por certas tendências veiculadas pelo texto.

\footnotetext{
A1: Fazer as pessoas sentirem a necessidade de comprar o produto.

A2: Quer as pessoas comprem as sandálias.

A3: Chamar atenção para a sandália.

A4: Destacar o produto.

A5: Que as pessoas queiram comprar o produto.

A6: Que todos comecem a usar o produto.

A7: Aumentar as vendas das sandálias Havaianas.

A8: Vender o produto anunciado.

A9: Mostrar o produto.
}

A10: O texto quer mostrar que a sandália é barata e acessível a todos.

Para realizarem uma interpretação mais consistente, os alunos precisam compreender que os textos multimodais devem ser lidos a partir da conjunção de todos os modos semióticos neles configurados. Como todo texto possui um 
significado, não basta apenas identificá-lo, é preciso lê-lo e interpretá-lo com base em todos os elementos verbais e visuais para compreender as implicações discursivas. Falta aos discentes (falta essa que será preenchida pelo professor) a percepção de que, na composição do anúncio há uma harmonia na articulação dos modos semióticos selecionados: imagem, texto verbal, cores e contexto, visto que um complementa o outro e contribuem para atrair a atenção do leitor, para convencê-lo ou persuadi-lo.

Os resultados da nossa investigação exploratória apontam para o desafio da escola de despertar o interesse do educando para os multiletramentos e capacitá-los para construir significados a partir dos diversos textos. Para isso, é necessário implantar uma cultura de práticas de leitura e escrita voltadas à formação crítica dos estudantes. Ler, nessa perspectiva, tem um significado amplo. Ao invés de uma micro análise direcionada para os aspectos estruturais da língua, a proposta é por uma macro análise em que os alunos possam estar atentos a significados voltados para questões situadas socialmente.

Desse modo, começamos nosso processo interventivo através da aplicação das sequências didáticas envolvendo leitura e interpretação de textos multimodais com o objetivo de criar ambientes coerentes com o mundo em que vivemos hoje, um mundo multimodal, preparando, assim, os alunos para que eles possam desenvolver estratégias para ler e entender textos de forma eficiente.

No início dessa pesquisa, constatamos através da nossa observação e da pesquisa exploratória que os alunos já tinham contato com textos multimodais no seu dia a dia, mas a maioria apresentavam dificuldades para realizar a leitura associando todos os elementos multissemióticos. Assim, iniciamos um trabalho com os referidos textos, no nosso caso específico, anúncio publicitário e charge, com o objetivo de auxiliarmos os alunos nas já mencionadas dificuldades de leitura.

Antes de abordar propriamente os gêneros que seriam trabalhados, direcionamos nosso olhar para o dia a dia do aluno, para os textos que são veiculados nos mais diversos meios de comunicação e são na sua maioria, constituídos por vários modos semióticos. Nessa fase inicial, apresentamos aos alunos diferentes textos multimodais como: tirinhas, charges, anúncios, para conjuntamente construirmos um conceito para multimodalidade, observando como os alunos realizavam a leitura e que aspectos eram considerados. E assim, 
inserirmos o aluno num tipo de letramento mais amplo, que exige novas formas de leitura e atribuição de sentido (ROJO, 2012). Por isso, iniciamos nosso processo interventivo expondo os textos seguintes no Datashow:

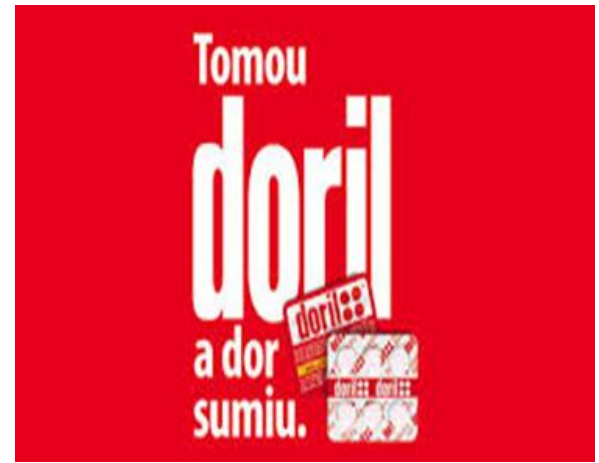

www.anunciospublicitarios.com
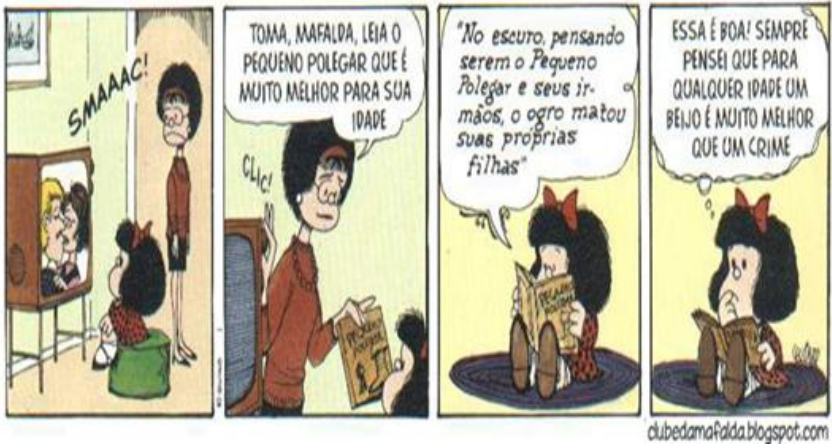

www.clubedamafaldablogspot.com

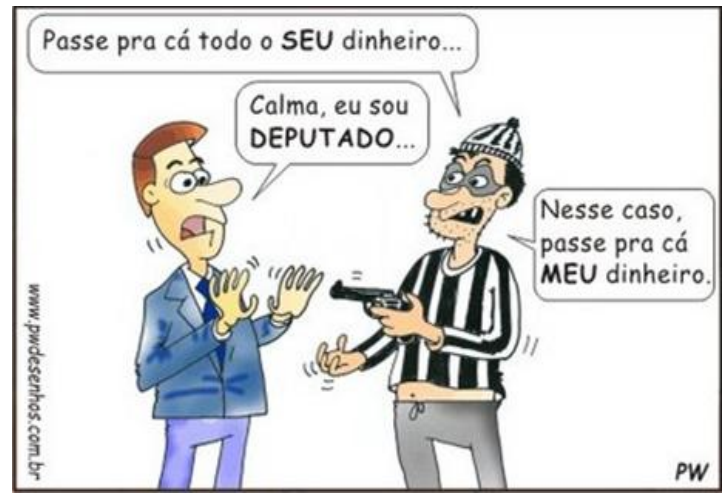

www.pwdesenhos.com.br

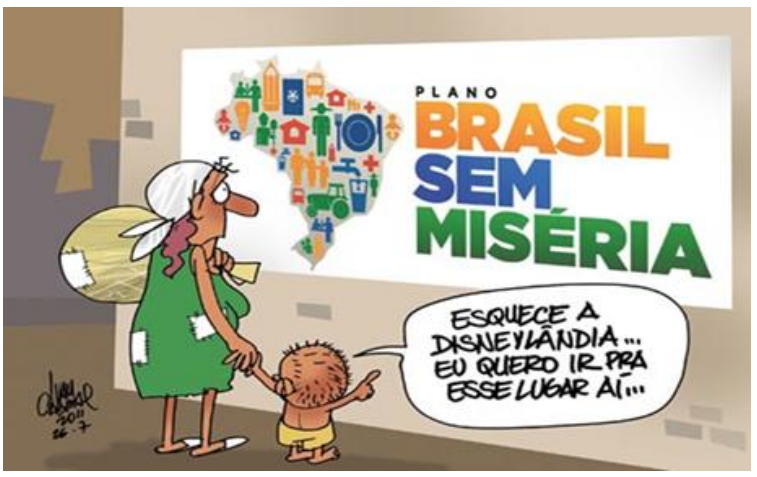

www.imagensdogoogle.com

As aulas iniciais foram destinadas principalmente ao conhecimento dos gêneros multimodais apresentados, analisando sua composição, sua esfera de produção, circulação e intencionalidade. Abordamos também a ideia de que os textos multimodais devem ser lidos a partir da inter-relação de todos os modos semióticos neles apresentados. Todos os elementos multissemióticos configurados nos textos possuem significação, por isso, devem ser lidos e interpretados para se compreender suas implicações discursivas, como destaca (JEWITT, 2011). Após a exposição dos textos e a análise das suas características, função social e valores veiculados, os alunos produziram pequenos textos expondo suas apreensões e entendimento sobre os textos multimodais. 
A1: O texto multimodal tem imagem e palavras.

A2: São textos com vários elementos como: texto escrito, imagens, cores.

A3: Este tem a parte escrita e as imagens.

A4: são formados por uma parte verbal e outra não verbal.

A5: São textos formados por parte escrita e por imagens, cores etc.

A6: Os textos multimodais têm uma parte verbal e outra não verbal.

A7: Acredito que são formados por vários elementos como: texto, imagens, cores, movimento, etc.

A8: Texto multimodal tem muitas coisas: imagens, cores, texto escrito.

A9: As imagens, a parte escrita, som, cores formam os textos multimodais.

A10: Esses textos tem a parte escrita, imagens e cores, tec.

Através das respostas apresentadas pelos alunos, verificamos que o conceito de textos multimodais foi bem assimilado. A maioria dos alunos apresentou argumentos afirmando que os textos multimodais são constituídos por elementos verbais e não verbais dentre os quais aparecem destacados cores, imagens, formato de letras, expressões entre outros.

\section{Considerações Finais}

Este trabalho se configurou como uma oportunidade de repensar o ensino de língua portuguesa, mais especificamente a formação de leitores, na perspectiva da multimodalidade. Para o enfoque dessa pesquisa, destacamos a relevância de se explorar os modos semióticos que compõem os textos, criando, assim, possibilidades para se desenvolver competências leitoras. Ampliando, dessa forma, a leitura de textos que extrapolam o modo semiótico verbal. Por isso, afirmamos que o trabalho do professor deve partir do princípio de que todas as formas de representação interferem na interpretação do texto. Os modos semióticos se complementam na composição do sentido. Os textos multimodais são, nesse sentido, uma ferramenta muito importante para fortalecer e atrair a atenção dos alunos, além de contribuírem para uma reflexão crítica e possibilitarem o engajamento social.

Demos início a essa pesquisa com a intenção de analisar o desenvolvimento da leitura dos alunos do $9^{\circ}$ ano do Ensino Fundamental sob a ótica da multimodalidade. Por isso, elaboramos uma proposta interventiva envolvendo 
atividades de leitura para serem desenvolvidas com os discentes, objetivando conduzi-los a ler de forma crítica, a partir da análise de todos os modos semióticos presentes nos textos trabalhados, no nosso caso específico, anúncio publicitário e charge. Diante dos resultados apresentados, afirmamos que o trabalho com a multimodalidade textual possibilita a compreensão de que as práticas comunicativas são construídas através de modos multissemióticos verbais e visuais. Os referidos modos conduzem ao um processo de construção de conhecimentos que exigem multiletramentos. Assim, percebemos que o desafio dos professores de língua portuguesa é grande; eles precisam encontrar meios para conduzirem os discentes a reconhecerem os modos semióticos e as ideologias que são veiculadas pelos textos. Para isso, é necessário um fortalecimento dos multiletramentos para que os alunos se tornem conscientes e críticos.

A partir da análise dos dados, pudemos perceber que as atividades propostas contribuíram para o desenvolvimento de uma leitura mais reflexiva. A análise de textos multimodais considerando a linguagem verbal e a não verbal favoreceram a efetivação de uma leitura mais profunda, contudo, o desenvolvimento do posicionamento crítico ainda necessita de mais prática para se efetivar. Assim, entendemos, que as práticas de leitura de textos multimodais favorecem 0 desenvolvimento de capacidades voltadas para a percepção dos sentidos implícitos na linguagem. Podemos argumentar, então, que a significação dos textos multimodais só se efetiva por meio da leitura de todos os modos presentes na sua construção.

A partir da análise dos dados coletados, verificamos que no contexto investigado houve uma resposta bem positiva e, que novas competências leitoras foram desenvolvidas, graças ao trabalho realizado com a leitura de gêneros textuais que unem elementos verbais e visuais. No entanto, é necessário que haja, por parte da escola, cada vez mais, a conscientização acerca da necessidade da formação dos alunos priorizando o desenvolvimento de competências relacionadas à leitura multimodal. O emprego de gêneros discursivos multimodais no contexto escolar possibilita que os alunos aprendam a interagir com a multimodalidade, tornando-os sujeitos conscientes e capazes de interpretar o que leem. 


\section{Referências}

BARTON, D.; HAMILTON, M. and IVANIC, R. (Eds.). Situated literacies. Reading and writing in context. London and New York, Routledge, 2000.

BRASIL. Secretaria de Educação Fundamental. Parâmetros curriculares nacionais: terceiro e quarto ciclos do ensino fundamental: língua portuguesa. Brasília: MEC/SEF, 2010.

DIONÍSIO, A. P. Gêneros multimodais e multiletramento. In: KARWOSKI, A. M.; GAYDECZKA, B.; BRITO, K. S. (Orgs.) Gêneros textuais reflexões e ensino. Rio de Janeiro: Lucerna, 2006.

DOLZ, J.; NOVERRAZ, M.; SCHNEUWLY, B. Sequências didáticas para o oral e a escrita: apresentação de um procedimento. In: ROXO, R.; CORDEIRO, G. S. Campinas, Mercado de Letras, 2004, pp. 95-128.

FREIRE, P. A importância do ato de ler. Cortez Editora. São Paulo: 2005.

GARCIA C. N. Culturas hibridas: estratégias para entrar e sair da modernidade. Trad.: A. R. Lessa e H. P. Cintrão. São Paulo: EDUSP, 2008 [1989].

JEWITT, C. An Introduction to multimodality. In: The Routledge Handbook of Multimodal Analysis. New York: Routledge, 2011, p. 1-27.

KRESS, G.; VAN LEEUWEN. Reading images: the grammar of visual design. London; New York: Routledge, 2006 [1996].

LEMKE, J. Multimídea Literacy Demands of the Scientific Curriculum. Linguistics and Education 10 (3): 247-271, 2000.

ROJO, R. Multiletramentos: práticas de leitura e escrita na contemporaneidade, 2010. Disponível em: < http://public.me.com/rrojo >. Acesso em Março de 2015. 2012. , Moura, E. Multiletramentos na escola [Orgs.]. São Paulo: Parábola Editorial, VAN DIJK, T. A. Cognição, discurso e interação. São Paulo: Cortez, 2011.

VIEIRA, J. A. Reflexões sobre a língua portuguesa: uma abordagem multimodal. Petrópolis, RJ: Vozes, 2007. 
Artigo recebido em: 20 de julho de 2015

Artigo aprovado em: 20 de setembro de 2015

\section{Sobre o autor:}

Marcos Nonato de Oliveira Licenciado em Letras (Português/Inglês) pela Universidade do Estado do Rio Grande do Norte/UERN (1993); Mestre em Linguística Aplicada pela Universidade Estadual do Ceará/UECE (2004); Doutor em Estudos da Linguagem pela Universidade Federal do Rio Grande do Norte/UFRN (2011). É professor (Adjunto IV) da UERN desde 1994, professor do Mestrado Profissional em Letras/PROFLETRAS, coordenador do PIBID/INGLÊS e Líder do grupo de pesquisa Estudos Aplicados em Línguas Estrangeiras/EALE, lotado no Departamento de Letras Estrangeiras/DLE, no campus profa. "Maria Elisa de Albuquerque Maia"/CAMEAM. 